\title{
Au@Void@ $\mathrm{TiO}_{2}$ Yolk-Shell Nanostructures as Catalysts for the Promotion of Oxidation Reactions at Cryogenic Temperatures
}

Ilkeun Lee, Ji Bong Joo, Yadong Yin, and Francisco Zaera*

Department of Chemistry, University of California, Riverside, CA 92521, USA

Email: zaera@ucr.edu

\begin{abstract}
A new gold-titania catalyst has been developed for cryogenic oxidations based on a yolk-shell nanoarchitecture. The synthesis of those structures involves the sequential deposition of a sacrificial silica layer and a titania shell around well-defined gold nanoparticles followed by removal of the silica via $\mathrm{NaOH}$ etching. The resulting catalyst contains an amorphous titania shell with sodium titanate and silicon impurities that proved critical for the cryogenic activity; removal of those via $\mathrm{HCl}$ treatment kills most of the catalytic conversion. Oxidation of carbon monoxide is possible with this Au@Void@ $\mathrm{TiO}_{2}$ catalyst at temperatures as low as $120 \mathrm{~K}$, by a mechanism different than the one operative at room temperature that involves a weakly-adsorbed $\mathrm{CO}$ species with a $\mathrm{C}-\mathrm{O}$ stretching frequency of $2162 \mathrm{~cm}^{-1}$, possibly at $\mathrm{Au}-\mathrm{TiO}_{2}$ interfacial sites.
\end{abstract}

Keywords: DRIFTS, Gold Catalysis, Low Temperature, Kinetics, Yolk-Shell, CO Oxidation.

\footnotetext{
* Corresponding author

(C) 2015. This manuscript version is made available under the Elsevier user license http://www.elsevier.com/open-access/userlicense/1.0/
} 


\section{Introduction}

Gold has traditionally been considered an inert material, which is why Haruta and coworkers cause a small revolution in the catalysis community when they reported that, in nanoparticle form, gold is capable to promote oxidation reactions under mild conditions [1]. In their original publication, those authors showed that carbon monoxide could be converted to carbon dioxide at temperatures as low as $200 \mathrm{~K}$ with the aide of what they described as "ultra-fine" gold particles dispersed on oxides of $3 \mathrm{~d}$ transition metals [2]. The use of this type of catalysts has been extended considerably since, to other oxidation processes as well as to other organic conversions [3-7]. Most reported reactions involving catalysts with gold in nanoparticle form take place around room temperatures and are activated, but we have recently shown that the promotion of carbon monoxide oxidation with gold-based catalysts is possible at temperatures as low as $120 \mathrm{~K}$ [8].

One limitation with the use of gold nanoparticles in catalysts is that they tend to sinter [9; 10$]$. This is a particularly severe problem with gold catalysts because those loose their activity once the nanoparticles reach a certain threshold size, a diameter on the order of a few nanometers [11]. Several approaches have been tested to stabilize gold nanoparticles on their solid supports [1214], and from those, the use of core-shell and yolk-shell nanostructures have shown particular promise $[15 ; 16]$. Such structures are now common in catalysis, and have found multiple uses $[17 ; 18]$. In fact, the success of the use of $\mathrm{Au} @ \mathrm{TiO}_{2}$ nanostructures for $\mathrm{CO}$ oxidation at room temperature has already been demonstrated by us [19] and others [20;21]. Not only the shells in those structures isolate individual $\mathrm{Au}$ nanoparticles so that they cannot cluster together, but they 
also provide a unique nanoreactor environment for catalytic reactions, in particular when yolkshell nanoarchitectures are used. It should be said that while the titania shells isolate the Au nanoparticles from each other, they do not prevent the transfer of gases in and out of the inner volume of the nanostructure or their access to the Au surfaces, and therefore do not affect the viability of the catalytic reactions $[22 ; 23]$.

In this report, we provide results from a study on the use of $\mathrm{Au} @$ Void@ $\mathrm{TiO}_{2}$ yolk-shell nanostructures as catalysts for the oxidation of carbon monoxide at cryogenic temperatures. For this, we have combined two observations from our previous work, namely: (1) that it is possible for these Au@Void@ $\mathrm{TiO}_{2}$ nanostructures to promote $\mathrm{CO}$ oxidation at room temperature [19]; and (2) that especially-treated $\mathrm{Au} / \mathrm{TiO}_{2}$ catalysts are capable of promoting $\mathrm{CO}$ oxidation at cryogenic temperatures [8]. The results from the second study are particular relevant here, because they highlighted the need to use amorphous titania supports treated with $\mathrm{NaOH}$ in order to form titanate sites. The same requirements were found to apply to the yolk-shell nanoarchitecture. The unique cryogenic activity of the Au@Void@ $\mathrm{TiO}_{2}$ catalyst is explained in terms of a synergistic interaction of $\mathrm{CO}$ and oxygen on unique sites involving defective titanatetype sites.

\section{Experimental Details}

The Au@Void@ $\mathrm{TiO}_{2}$ catalysts were prepared by following a procedure similar to that already reported in the past [19]. The main synthetic steps are depicted schematically in Figure 1. 
Briefly, Au nanoparticles of approximately $15 \mathrm{~nm}$ in diameter were first grown from a mixture of $\mathrm{HAuCl}_{4} \cdot 3 \mathrm{H}_{2} \mathrm{O}$, sodium citrate, and polyvinylpyrrolidone (PVP) in water. Next, a sacrificial silica layer ( $200 \mathrm{~nm}$ in diameter) was grown on top by a sol-gel process with tetraethyl orthosilicate (TEOS), and an outer titania shell ( $20 \mathrm{~nm}$ in thickness) was deposited afterward using tetrabutyl titanate (TBOT). Finally, the silica layer was etched away using an aqueous $\mathrm{NaOH}$ solution. This catalyst is denoted here as Au@Void@ $\mathrm{TiO}_{2}-(\mathrm{A})$. In order to test the effect of the nature of the titania phase on the oxidation catalysis, two more catalysts were prepared: (1) a Au@Void@ $\mathrm{TiO}_{2}-(\mathrm{A})+\mathrm{HCl}$, obtained by treating the Au@Void@ $\mathrm{TiO}_{2}-(\mathrm{A})$ original solid with $\mathrm{HCl}$ to remove the sodium left behind in the silica-etching step; and (2) a second $\mathrm{Au} @$ Void@ $\mathrm{TiO}_{2}-(\mathrm{A})+\mathrm{HCl}+\mathrm{NaOH}$ sample where sodium was brought back to the $\mathrm{HCl}$-treated solid by exposing it to $\mathrm{NaOH}$. These samples were rinsed with pure water several times after the treatment to remove any excess of the acid or base; no chlorine at all was ever detected in the XPS data. The details of the procedures used are described in our earlier publication [8].

Transmission electron microscopy (TEM) images of the resulting structures were taken using a Tecnai T12 instrument. X-ray diffraction (XRD) measurements were acquired with a Bruker D8 Advance diffractometer and $\mathrm{Cu} \mathrm{K} \alpha$ radiation $(\lambda=1.5406 \AA)$. X-ray photoelectron spectroscopy (XPS) data were obtained with a Kratos analytical AXIS instrument equipped with a $165-\mathrm{mm}-$ mean-radius semi-hemispherical electron energy analyzer and a monochromatized $\mathrm{Al}$ anode.

Diffuse reflectance infrared absorption spectra (DRIFTS) were acquired using a Bruker Tensor 27 FTIR interferometer and a Harrick variable-temperature Praying Mantis DRIFTS reaction chamber, which acted as a batch reactor. The catalysts were sequentially pretreated ex situ in 
flowing $\mathrm{H}_{2}(775 \mathrm{~K}, 6 \mathrm{~h}), \mathrm{O}_{2}(675 \mathrm{~K}, 6 \mathrm{~h})$, and $\mathrm{H}_{2}$ again $(475 \mathrm{~K}, 6 \mathrm{~h})$ prior to their use. All adsorption and kinetic measurements were performed in situ as the catalysts were exposed to the appropriate gas mixtures. The raw spectra are reported in pseudo-absorbance units, calculated from the original reflectivity data, and turnover numbers (TONs, in units of $\mathrm{CO}_{2}$ molecules produced per Au surface atom) and turnover frequencies (TOFs, as TON per time in seconds) were estimated from those via integration of the appropriate peaks after calibrations using known pressures of $\mathrm{CO}$ and $\mathrm{CO}_{2}$ at each temperature to account for possible condensation and other effects, as discussed in more detail in a previous publication [8]. The Au surface sites were estimated from the nanoparticle size determined by TEM. Typical CO oxidation reactions were carried out with mixtures of 200 Torr of $\mathrm{CO}$ and 200 Torr of $\mathrm{O}_{2}$, but other experiments were also performed with either one gas alone or with none, as described below. Evacuation of the IR reactor was done by using a mechanical pump capable of reaching pressures in the low mTorr range.

\section{Results and Discussion}

The yolk-shell nanostructures were first characterized by using several techniques. Typical TEM images of the Au@Void@ $\mathrm{TiO}_{2}-(\mathrm{A})$ sample, shown in Figure 2 (top), attest to the yolk-shell structure of these samples. In addition, XRD measurements indicated that the titania shells in the yolk-shell nanostructures consisted mainly of amorphous titania but were not pure, since they contained small portions of sodium titanate. XPS analysis corroborated the presence of sodium 
(Figure 3, second from right panel, bottom blue trace), and also indicated the presence of some residual silicon (Figure 3, right panel, bottom blue trace).

TEM images of the other two catalysts, provided in Figure 2, indicate that the yolk-shell nanoarchitecture is preserved all throughout all the chemical steps. XPS data, shown in Figure 3, were used to assess the success of each step (the broad feature seen for the Au@Void@ $\mathrm{TiO}_{2^{-}}$ (A) $+\mathrm{HCl}$ sample in the $\mathrm{Na}$ 1s Figure 3, 3rd panel, is actually from Ti LMM photoelectrons; there is no sodium left at all in that sample), and to establish two more important changes, namely: (1) that the $\mathrm{HCl}$ treatment brings out the residual silica to the surface, which apparently is then removed more efficiently during the subsequent second $\mathrm{NaOH}$ step (Figure 3, right panel, Si 2p peak at $102.0 \mathrm{eV}$-typical of $\mathrm{SiO}_{2}-$ ); and (2) that the $\mathrm{HCl}$-treated sample appears to have a larger concentration of surface hydroxo groups, as indicated by the larger O 1s XPS peak around 531.5 $\mathrm{eV}$ (an approximately doubling of the signal intensity in the high-binding energy shoulder in Figure 3, second from right panel). This latter change is reversible.

Typical infrared spectra obtained during reaction are displayed in Figure 4. The traces there correspond to reactions carried out by using both the original Au@Void@ $\mathrm{TiO}_{2}-(\mathrm{A})$ catalyst and the Au@Void@ $\mathrm{TiO}_{2}-(\mathrm{A})+\mathrm{HCl}$ sample made via $\mathrm{HCl}$ treatment, at either 120 or $350 \mathrm{~K}$; all of these traces were acquired after 60 min of reaction. The spectra are somewhat complex, exhibiting signals in several wavenumber ranges, but most of the peaks observed are characteristic of the solids themselves and do not change during reaction. Specifically, the features seen between 1300 and $1800 \mathrm{~cm}^{-1}$ correspond to carbonate and formate species [24], and those in the $3500-3800 \mathrm{~cm}^{-1}$ wavenumber range are associated with hydroxo surface moieties 
[25]. The peaks relevant to our CO oxidation studies are those in the 2050-2250 and 2300-2400 $\mathrm{cm}^{-1}$ wavenumber ranges, which correspond to the reactant $(\mathrm{CO})$ and the product $\left(\mathrm{CO}_{2}\right)$, respectively.

The evolution of those features as a function of reaction time is displayed in Figure 5 for reactions with the original $\mathrm{Au} @$ Void@ $\mathrm{TiO}_{2}-(\mathrm{A})$ catalyst at 120 (left) and 350 (right) $\mathrm{K}$. In both cases, the $\mathrm{CO}$ features decrease in intensity as those for $\mathrm{CO}_{2}$ grow, a clear indication of the catalytic conversion of the former into the latter. Each IR absorption feature in the right panel appears as a doublet, with the typical shape expected for the gas-phase species. The corresponding features at $120 \mathrm{~K}$ (left), on the other hand, look different: the $\mathrm{CO}_{2}$ signal is reduced to one single peak, and the $\mathrm{CO}$ signal grows a third sharp peak on top of those from the gas species, indicating condensation of the gases within the pores of the catalyst, a fact that complicates the kinetic measurements but that was already discussed in great detail and resolved in a previous publication [8]. This is the reason for the leveling off that is typically seen at low temperatures in the DRIFTS signal intensity from $\mathrm{CO}_{2}$ in the kinetic measurements reported next, and why we have chosen to use the turnover frequencies (TOF) after 60 min of reaction as the parameter of merit to contrast the performance of our yolk-shell catalysts here. It should be indicated that, in spite of this complication, DRIFTS is still an ideal method to follow the catalytic conversion, because it gives information about all adsorbed, condensed, and gas-phase species, and because since under cryogenic conditions the product is not released into the gas phase, it cannot be detected by gas analysis techniques such as gas chromatography or mass spectrometry. 
The conversion of $\mathrm{CO}$ to $\mathrm{CO}_{2}$ with our catalysts was followed at different temperatures, and reported as TON (after appropriate DRIFTS signal calibration) versus reaction time in Figure 6. Data are shown there in three panels, for the three catalysts, and for several temperatures in the range between 120 and $350 \mathrm{~K}$. It is clear from these results that the original $\mathrm{Au} @ \mathrm{Void} @ \mathrm{TiO}_{2}-$ (A) catalyst (left panel) is by far the most active of the three (notice the factor of four amplification used in the two right panels of Figure 6). In that case, high conversions are seen at higher temperatures, with maximum activity at $350 \mathrm{~K}$, and a decrease is observed with decreasing temperature down to $250 \mathrm{~K}$, below which the conversion is undetectable within our experimental error. This behavior is typical of thermally activated chemical processes, and mimics what has been seen with other gold-base catalysts in the past. However, a renewed activity is also observed here at lower temperatures, below $200 \mathrm{~K}$, with the activity increasing with decreasing temperature and reaching values at $120 \mathrm{~K}$ comparable to those seen at $350 \mathrm{~K}$. It is this cryogenic activity that is the focus of our present report. A similar behavior was reported by us with regular $\mathrm{Au} / \mathrm{TiO}_{2}$ catalysts treated with $\mathrm{NaOH}[8]$, but there is otherwise no other precedent that we are aware of for such low-temperature activity.

With the yolk-shell catalysts treated with either $\mathrm{HCl}$ alone (Figure 6, center panel) or $\mathrm{HCl}+$ $\mathrm{NaOH}$ (right), reasonable $\mathrm{CO}$ oxidation activity can be seen at $350 \mathrm{~K}$, even if not as high as with the original catalyst, but no low-temperature conversion is observed with either. It is clear that only the original Au@Void@ $\mathrm{TiO}_{2}-(\mathrm{A})$ catalyst displays the interesting cryogenic catalysis discussed above. In that sense, these catalysts do differ from the ones made out of nonnanostructured titania, in which case the cryogenic activity could be reversibly reinstated upon treatment with $\mathrm{NaOH}$. It is possible that in this new case the $\mathrm{HCl}$ and $\mathrm{NaOH}$ treatments not only 
remove and reinstate vital sodium titanate sites, respectively, but also creates new titanium silicate surface sites, different to those present in the untreated catalyst (Figure 3). Clearly, not only the introduction of sodium but also the presence of silicon atoms affects the performance of these catalysts, even if the effect of the latter is not fully understood at present. The contrast in performance among the three catalysts studied here can be better seen in the summary of their activities versus temperature provided in Figure 7, where the performance is reported as TOF at the 60 min reaction time mark. Again, the Au@Void@ $\mathrm{TiO}_{2}-(\mathrm{A})$ catalyst is by far the most active of the three at all temperatures, and the only one with measurable activity below $250 \mathrm{~K}$.

In order to test the mechanism of the $\mathrm{CO}$ oxidation reaction observed with the $\mathrm{Au} @ \mathrm{Void} @ \mathrm{TiO}_{2^{-}}$ (A) catalyst at both room and cryogenic temperatures, a series of tests were carried out by varying the sequence in which the gases were fed to the catalyst [8]. Five procedures were explored: (1) adding a $\mathrm{CO}+\mathrm{O}_{2}$ mixture all at once; (2 and 3) adding one reactant $\left(\mathrm{CO}\right.$ or $\left.\mathrm{O}_{2}\right)$ first, then toping off the reactor with the second $\left(\mathrm{O}_{2}\right.$ or $\left.\mathrm{CO}\right)$; and (4 and 5) sequentially adding one reactant $\left(\mathrm{CO}\right.$ or $\left.\mathrm{O}_{2}\right)$ first, pumping the cell to recuperate the starting vacuum environment, and adding the second $\left(\mathrm{O}_{2}\right.$ or $\left.\mathrm{CO}\right)$ reactant. The resulting kinetic runs, in the form of TON versus time, are reported in Figure 8. High reactivity is always seen in cases where both gases are present in the gas mixture, at both temperatures, even if there are subtle differences depending on the order in which the reactants are added to the mixture (possibly because of issues related to gas mixing). In addition, however, $\mathrm{CO}_{2}$ is also produced at $120 \mathrm{~K}$ (but not at $350 \mathrm{~K}$ ) if $\mathrm{CO}$ is fed first, the chamber pumped, and the $\mathrm{O}_{2}$ provided afterwards. This suggests that at cryogenic temperatures $\mathrm{CO}$ adsorbs on surface sites strongly enough to survive pumping of the system, and reacts with the oxygen added afterwards. That may in fact be also the reason 
why the best catalytic performance at $120 \mathrm{~K}$ is seen if the $\mathrm{CO}$ is fed into the reaction volume first ("CO, Then $\mathrm{O}_{2}$ " red trace in left panel of Figure 8). At $350 \mathrm{~K}$, by contrast, there is no evidence for the formation of any $\mathrm{CO}$ or oxygen intermediates in the sequential dosing experiments (the small $\mathrm{CO}_{2}$ production in the $\mathrm{O}_{2}$-pump-CO experiment may reflect the conversion of some oxygen-rich sites on the titania surface).

The nature of the $\mathrm{CO}$ surface species formed at $120 \mathrm{~K}$ can be inferred from the DRIFTS data. The relevant spectra, for the original Au@Void@ $\mathrm{TiO}_{2}-(\mathrm{A})$ catalyst, are provided in Figure 9. The traces in the left panel correspond to the CO-pump- $\mathrm{O}_{2}$ dosing sequence. Exposure to $\mathrm{CO}$ results in the development of the peaks in the $2050-2250 \mathrm{~cm}^{-1}$ wavenumber region reported above, and indicates adsorption on the catalyst surface. Subsequent pumping leads to the disappearance of all DRIFTS signals, suggesting full desorption of the adsorbed species. However, introduction of $\mathrm{O}_{2}$ afterwards is accompanied by the reinstating of some adsorbed $\mathrm{CO}$ signal, indicating that an "IR silent" CO adsorbate is still present on the surface at the pumping stage, and that such species is converted into another adsorption mode upon interaction with oxygen. The main CO peak at this stage is centered around $2162 \mathrm{~cm}^{-1}$, and slowly goes away (after its initial growth) as a second feature evolves at $2350 \mathrm{~cm}^{-1}$, evidence of the oxidation of $\mathrm{CO}$ to $\mathrm{CO}_{2}$. No evidence for a similar intermediate can be extracted from the DRIFTS traces recorded for the CO-pump- $\mathrm{O}_{2}$ experiment at $350 \mathrm{~K}$ (Figure 9, right panel), and no evidence for new unexpected chemistry is seen in the $\mathrm{O}_{2}$-pump-CO experiments at $120 \mathrm{~K}$ either (Figure 8, center panel). All this matches the behavior previously observed with regular $\mathrm{Au} / \mathrm{TiO}_{2}-\mathrm{P} 25$ catalysts [8]. 


\section{Conclusions}

The catalytic performance of $\mathrm{Au} @ \mathrm{Void} @ \mathrm{TiO}_{2}-(\mathrm{A})$ yolk-shell nanostructures for lowtemperature $\mathrm{CO}$ oxidation was probed by means of DRIFTS experiments. The original sample was found to display activity around and above room temperature, as many other Aunanoparticle-based catalysts, but also at cryogenic temperatures. Most of the catalytic activity is lost upon treatment of the catalyst with $\mathrm{HCl}$, which removes the sodium left behind by the etching step of the catalyst synthesis, and cannot be restored upon further $\mathrm{NaOH}$ treatments. It was determined that the cryogenic catalytic activity requires amorphous titanate-type sites. This is similar to what was reported with $\mathrm{Au} / \mathrm{TiO}_{2}$ catalysts earlier [8], except that in this case it was found that silicon impurities may also play a role.

The cryogenic reaction takes place by a mechanism different to that responsible for oxidation at room temperature. A weakly adsorbed $\mathrm{CO}$ precursor was identified at $120 \mathrm{~K}$ by its signature infrared absorption peak at $\sim 2160 \mathrm{~cm}^{-1}$. In analogy with the observations using our previous cryogenic-active $\mathrm{Au} / \mathrm{TiO}_{2}$ catalysts, we assume that this intermediate forms at the gold-titania interface, and reacts with atomic oxygen from dissociation of $\mathrm{O}_{2}$ on gold. Interestingly, the first $\mathrm{CO}$ precursor in the mechanism on amorphous non-nanostructured titania, seen at $2180 \mathrm{~cm}^{-1}$ [8], was not observed with the yolk-shell catalysts.

\section{Acknowledgements}


This work was supported by the U.S. Department of Energy, Office of Science, Basic Energy

Sciences, Chemical Sciences, Geosciences, \& Biosciences (CSGB) Division, under Award No.

DE-SC0002247. The XPS instrument used in this research was acquired with funds from NSF Grant DMR-0958796. FZ is the Director of the University of California, Riverside Center for Catalysis. More details can be found at catalysis.ucr.edu.

\section{References}

[1] M. Haruta, Angew. Chem., Int. Ed. 53 (2014) 52-56.

[2] M. Haruta, T. Kobayashi, H. Sano, N. Yamada, Chem. Lett. 16 (1987) 405-408.

[3] G. J. Hutchings, M. Haruta, Appl. Catal. A 291 (2005) 2-5.

[4] M. Haruta, Nature 437 (2005) 1098-1099.

[5] G. C. Bond, C. Louis, D. T. Thompson, Catalysis by Gold, Imperial College Press, World Scientific Publishing, London, 2006.

[6] A. Corma, H. Garcia, Chem. Soc. Rev. 37 (2008) 2096-2126.

[7] A. Corma, A. Leyva-Pérez, M. J. Sabater, Chem. Rev. 111 (2011) 1657-1712.

[8] I. Lee, F. Zaera, J. Catal. 319 (2014) 155-162.

[9] M. Chen, D. W. Goodman, Chem. Soc. Rev. 37 (2008) 1860-1870.

[10] R. Tiruvalam, Q. He, A. A. Herzing, J. Pritchard, N. Dimitratos, J. A. Lopez-Sanchez, J. K. Edwards, A. F. Carley, G. J. Hutchings, C. J. Kiely, J. Phys. Conf. Ser. 371 (2012) 012028.

[11] M. Valden, X. Lai, D. W. Goodman, Science 281 (1998) 1647-1650.

[12] N. R. Shiju, V. V. Guliants, Appl. Catal. A 356 (2009) 1-17. 
[13] A. B. Laursen, K. T. Højholt, L. F. Lundegaard, S. B. Simonsen, S. Helveg, F. Schüth, M. Paul, J.-D. Grunwaldt, S. Kegnæs, C. H. Christensen, K. Egeblad, Angew. Chem., Int. Ed. 49 (2010) 3504-3507.

[14] Z. Ma, S. Dai, ACS Catal. 1 (2011) 805-818.

[15] J. Li, H. C. Zeng, Angew. Chem., Int. Ed. 44 (2005) 4342-4345.

[16] F. Zaera, Chem. Soc. Rev. 42 (2013) 2746-2762.

[17] W. Schärtl, Nanoscale 2 (2010) 829-843.

[18] G. Li, Z. Tang, Nanoscale 6 (2014) 3995-4011.

[19] I. Lee, J. B. Joo, Y. Yin, F. Zaera, Angew. Chem., Int. Ed. 50 (2011) 10208-10211.

[20] Y. Chen, B. Zhu, M. Yao, S. Wang, S. Zhang, Catal. Commun. 11 (2010) 1003-1007.

[21] Q. Zhang, I. Lee, J. B. Joo, F. Zaera, Y. Yin, Acc. Chem. Res. 46 (2012) 1816-1824.

[22] X. Liang, J. Li, J. B. Joo, A. Gutiérrez, A. Tillekaratne, I. Lee, Y. Yin, F. Zaera, Angew. Chem., Int. Ed. 51 (2012) 8034-8036.

[23] J. Li, X. Liang, J. B. Joo, I. Lee, Y. Yin, F. Zaera, J. Phys. Chem. C 117 (2013) 2004320053.

[24] Y. Denkwitz, B. Schumacher, G. Kučerová, R. J. Behm, J. Catal. 267 (2009) 78-88.

[25] J. A. Toledo-Antonio, S. Capula, M. A. Cortés-Jácome, C. Angeles-Chávez, E. LópezSalinas, G. Ferrat, J. Navarrete, J. Escobar, J. Phys. Chem. C 111 (2007) 10799-10805. 


\section{Figure Captions}

Figure 1. Scheme of the synthesis of the Au@Void@ $\mathrm{TiO}_{2}$ yolk-shell nanostructures used here as catalysts for the cryogenic oxidation of carbon monoxide. Of critical importance to the low-temperature catalytic activity is the use of a sacrificial silica layer and its removal using $\mathrm{NaOH}$ as the etchant, because that appears to leave behind crucial sodium titanate and/or titanium silicate sites.

Figure 2. Transmission electron microscopy (TEM) images of the three catalysts studied here, the original Au@Void@ $\mathrm{TiO}_{2}-(\mathrm{A})$ nanostructure (top) and samples obtained after sequential $\mathrm{HCl}$ (Au@Void@ $\mathrm{TiO}_{2}-(\mathrm{A})+\mathrm{HCl}$, center) and $\mathrm{NaOH}\left(\mathrm{Au} @\right.$ Void@ $\mathrm{TiO}_{2}$ (A) $+\mathrm{HCl}+\mathrm{NaOH}$, bottom) treatments.

Figure 3. Ti 2p (left), O 1s (second from left), Na 1s (second from right) and Si 2p (right) X-ray photoelectron spectroscopy (XPS) data for the Au@Void@ $\mathrm{TiO}_{2}-(\mathrm{A})$ (bottom, blue traces), Au@Void@ $\mathrm{TiO}_{2}-(\mathrm{A})+\mathrm{HCl}$ (middle, red traces), and Au@Void@ $\mathrm{TiO}_{2}-$ (A) $+\mathrm{HCl}+\mathrm{NaOH}$ (top, green traces) catalysts. The removal of sodium, the exposure of silicon on the surface, and the formation of extra $\mathrm{OH}$ surface groups upon $\mathrm{HCl}$ treatment are all evident from these data.

Figure 4. Typical diffuse-reflectance infrared Fourier-transform spectroscopy (DRIFTS) data for the Au@Void@ $\mathrm{TiO}_{2}-(\mathrm{A})$ (1st and 3rd traces from bottom, light colors) and $\mathrm{Au} @$ Void@ $\mathrm{TiO}_{2}-(\mathrm{A})+\mathrm{HCl}$ (1st and 3rd traces from top, dark colors) during $\mathrm{CO}+\mathrm{O}_{2}$ 
oxidation reactions (after 60 min of conversion) at 120 (top two, blue traces) and 350 $\mathrm{K}$ (bottom two, red traces). Mixtures of 200 Torr of $\mathrm{CO}$ and 200 Torr of $\mathrm{O}_{2}$ were used here and in all the other kinetic studies.

Figure 5. DRIFTS data in the $1600-2600 \mathrm{~cm}^{-1}$ region as a function of time for the conversion of $\mathrm{CO}+\mathrm{O}_{2}$ mixtures on the original Au@Void@ $\mathrm{TiO}_{2}-(\mathrm{A})$ catalyst. The consumption of $\mathrm{CO}$ and the formation of $\mathrm{CO}_{2}$ were followed by using the intensities of the DRIFTS absorption seen around 2050-2250 and 2300-2400 $\mathrm{cm}^{-1}$, respectively.

Figure 6. Kinetics of reaction, in terms of $\mathrm{TON}\left(\mathrm{CO}_{2}\right.$ molecules per Au surface atom) versus time, for the conversion of $\mathrm{CO}+\mathrm{O}_{2}$ mixtures at various temperatures $(120,150,200$, 250, 300, and $350 \mathrm{~K}$ ) with our three catalysts: Au@Void@ $\mathrm{TiO}_{2}-(\mathrm{A})$ (left panel), Au@Void@ $\mathrm{TiO}_{2}-(\mathrm{A})+\mathrm{HCl}$ (center), and Au@Void@ $\mathrm{TiO}_{2}-(\mathrm{A})+\mathrm{HCl}+\mathrm{NaOH}$ (right). The first sample is the most active at all temperatures, and the only one that can promote oxidation at cryogenic temperatures.

Figure 7. Turnover frequencies (TOF, as TON per seconds), estimated after 60 minutes of reaction, versus reaction temperature for all three catalysts. The data were obtained by estimating the slopes of the TON vs. time traces at the 60-min mark in Figure 6.

Figure 8. Kinetics, in the form of TON vs. time, for the Au@Void@ $\mathrm{TiO}_{2}-(\mathrm{A})$ catalyst at 120 (left panel) and 350 (right) $\mathrm{K}$, obtained in experiments performed using different sequences of gas feeding, namely: (1) adding $\mathrm{CO}+\mathrm{O}_{2}$ mixtures (purple short-dash 
traces); (2) adding $\mathrm{CO}$, then $\mathrm{O}_{2}$ (red solid traces): (3) adding $\mathrm{O}_{2}$, then $\mathrm{CO}$ (grey dashdot traces); (4) adding $\mathrm{CO}$, pumping, then adding $\mathrm{O}_{2}$ (blue solid traces); and (5) adding $\mathrm{O}_{2}$, pumping, then adding $\mathrm{CO}$ (green short-dash traces). The activity seen in the CO-pump- $\mathrm{O}_{2}$ case at $120 \mathrm{~K}$ indicates the formation of a weakly adsorbed $\mathrm{CO}$ intermediate at that temperature.

Figure 9. DRIFTS traces for selected experiments with the Au@Void@ $\mathrm{TiO}_{2}-(\mathrm{A})$ catalyst. Left: CO-pump- $\mathrm{O}_{2}$ experiment at $120 \mathrm{~K}$. Center: $\mathrm{O}_{2}$-pump-CO experiment at $120 \mathrm{~K}$. Right: CO-pump- $\mathrm{O}_{2}$ experiment at $350 \mathrm{~K}$. Only in the first case an adsorbed $\mathrm{CO}$ intermediate can be identified, by its infrared absorption at $2162 \mathrm{~cm}^{-1}$. 


\section{Au@Void@ $\mathrm{TiO}_{2}$ Synthetic Strategy}

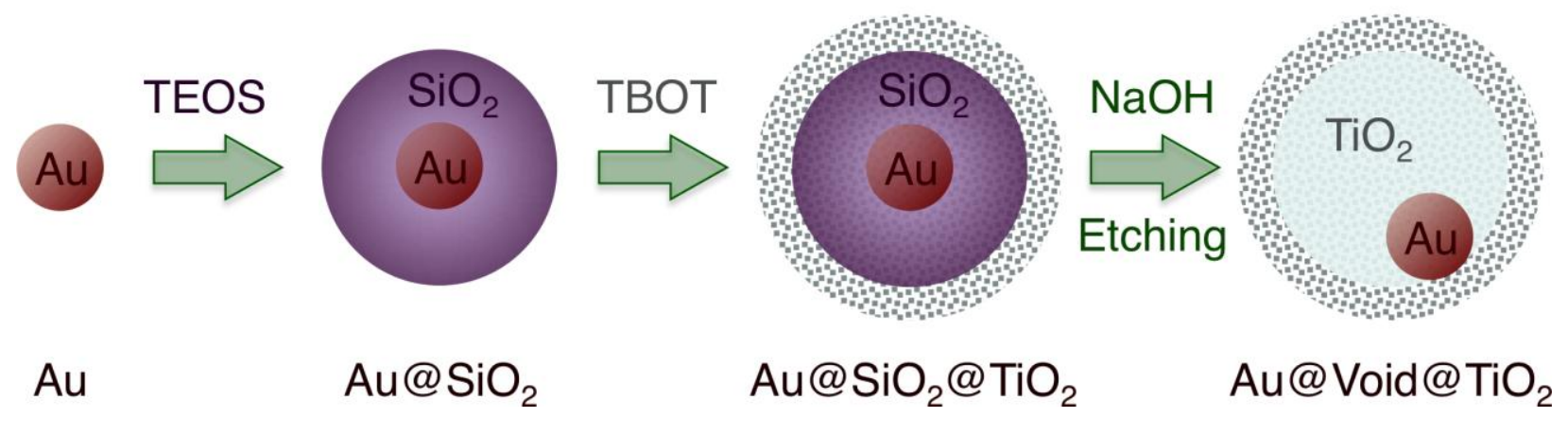

Figure 1 

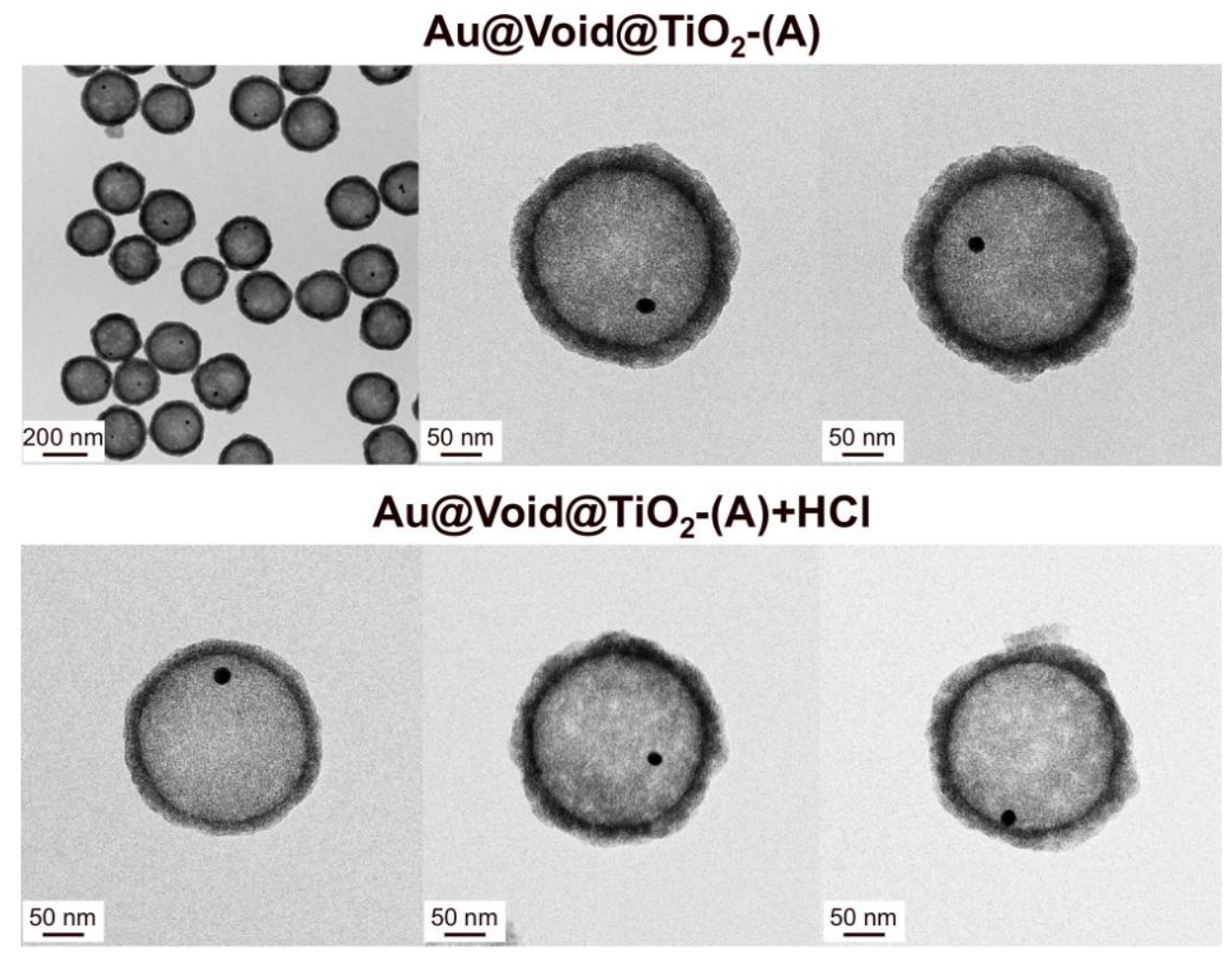

Au@Void@TiO $-(A)+H C l+N a O H$

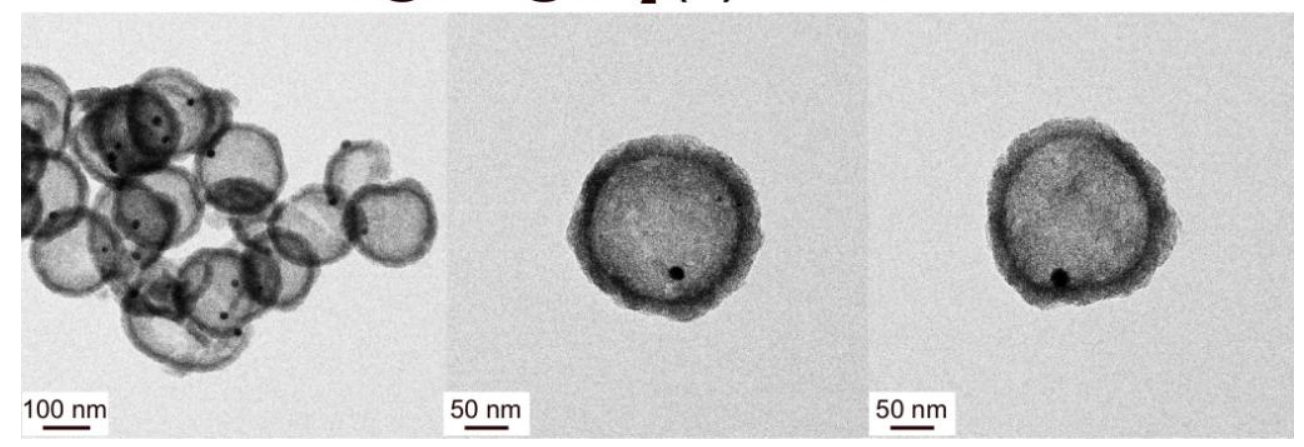

Figure 2 


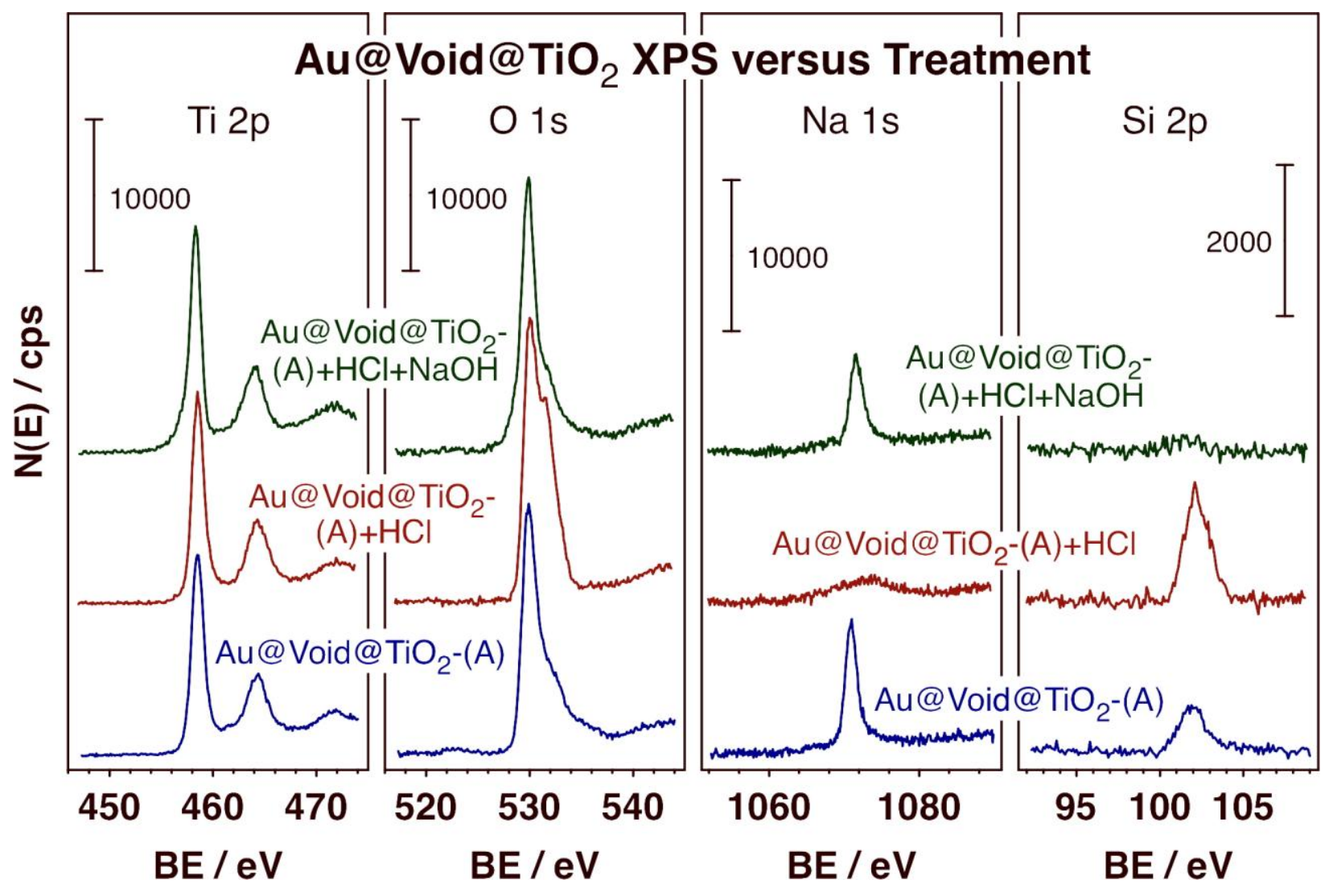

Figure 3 


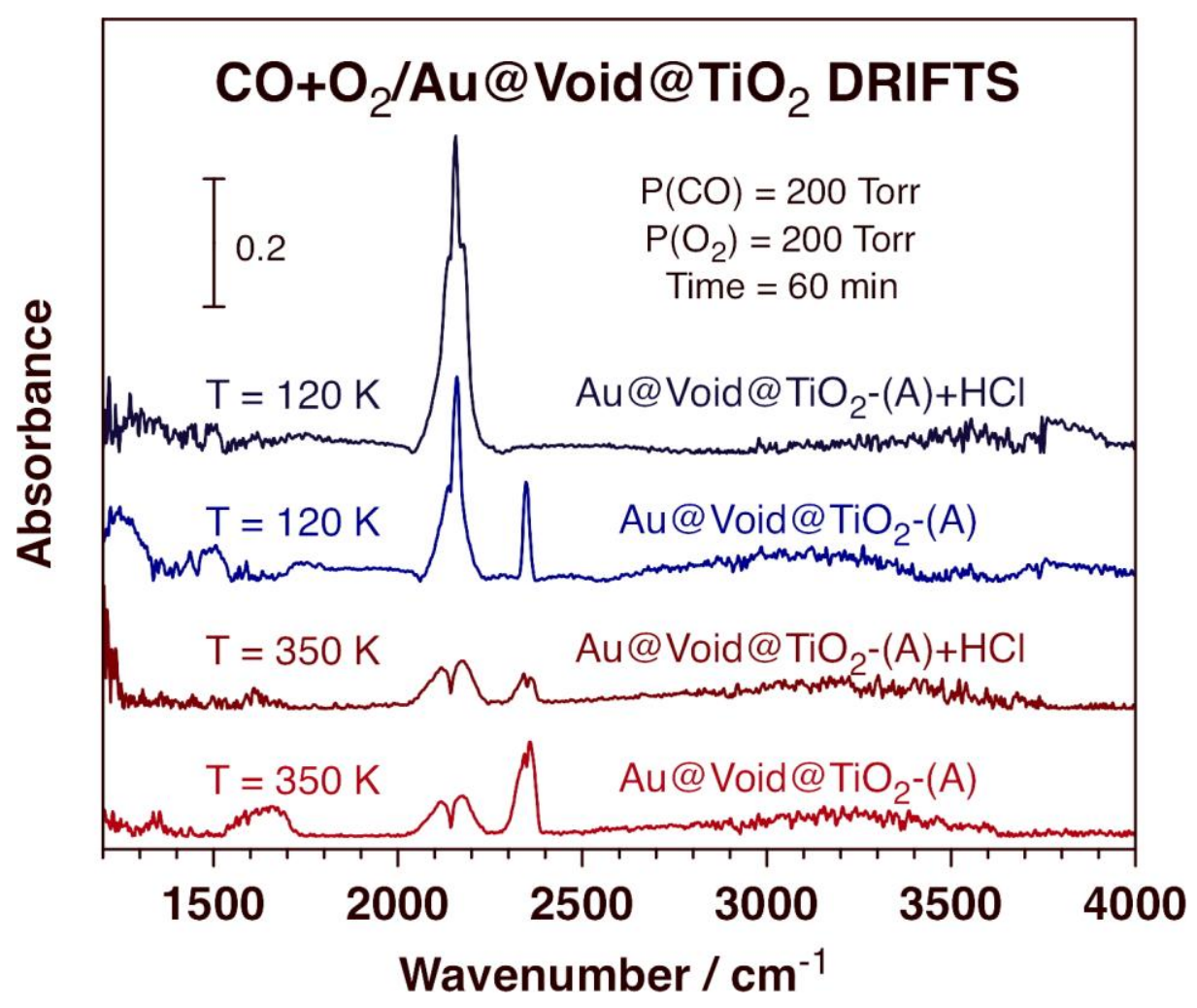

Figure 4 


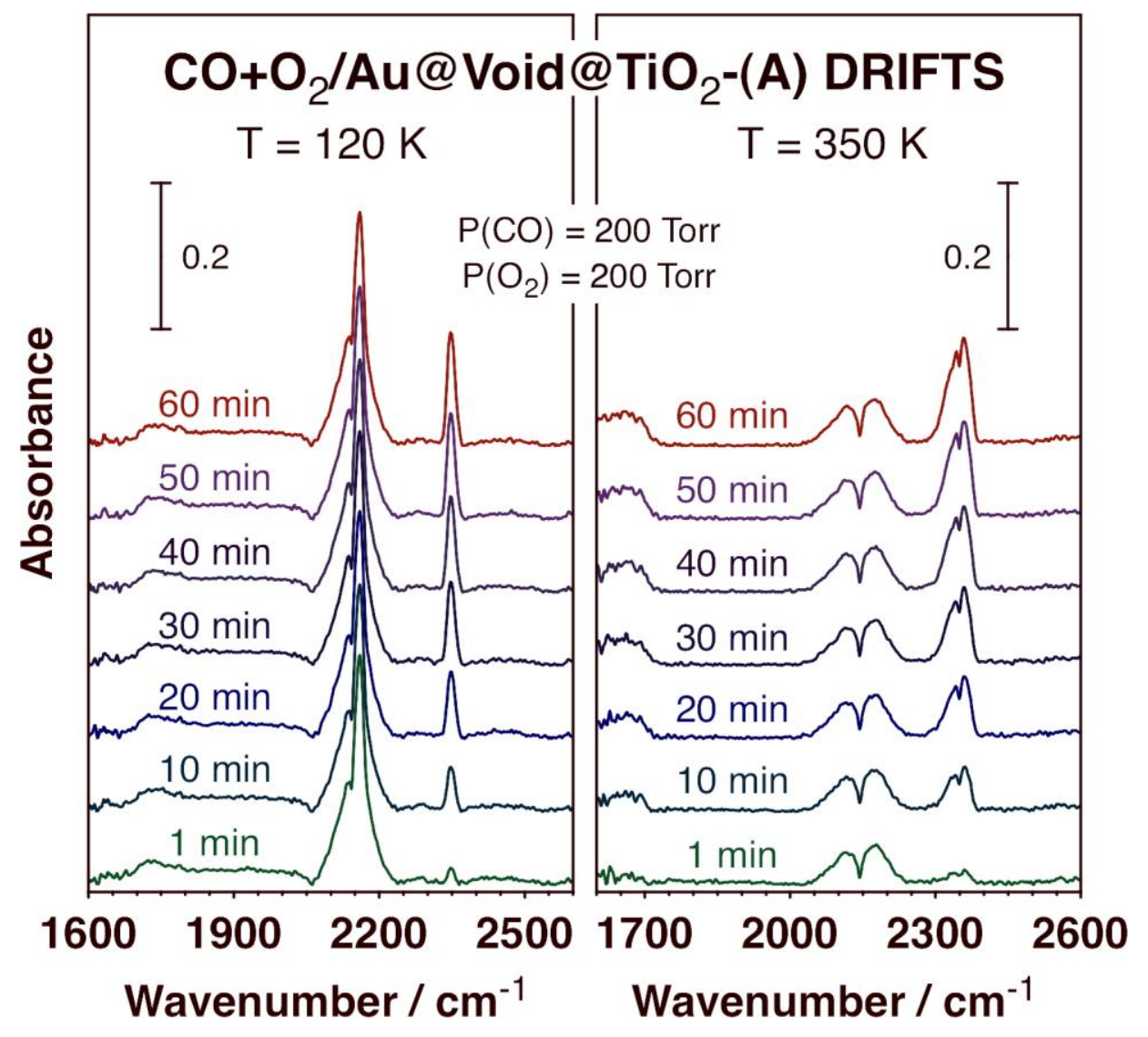

Figure 5 


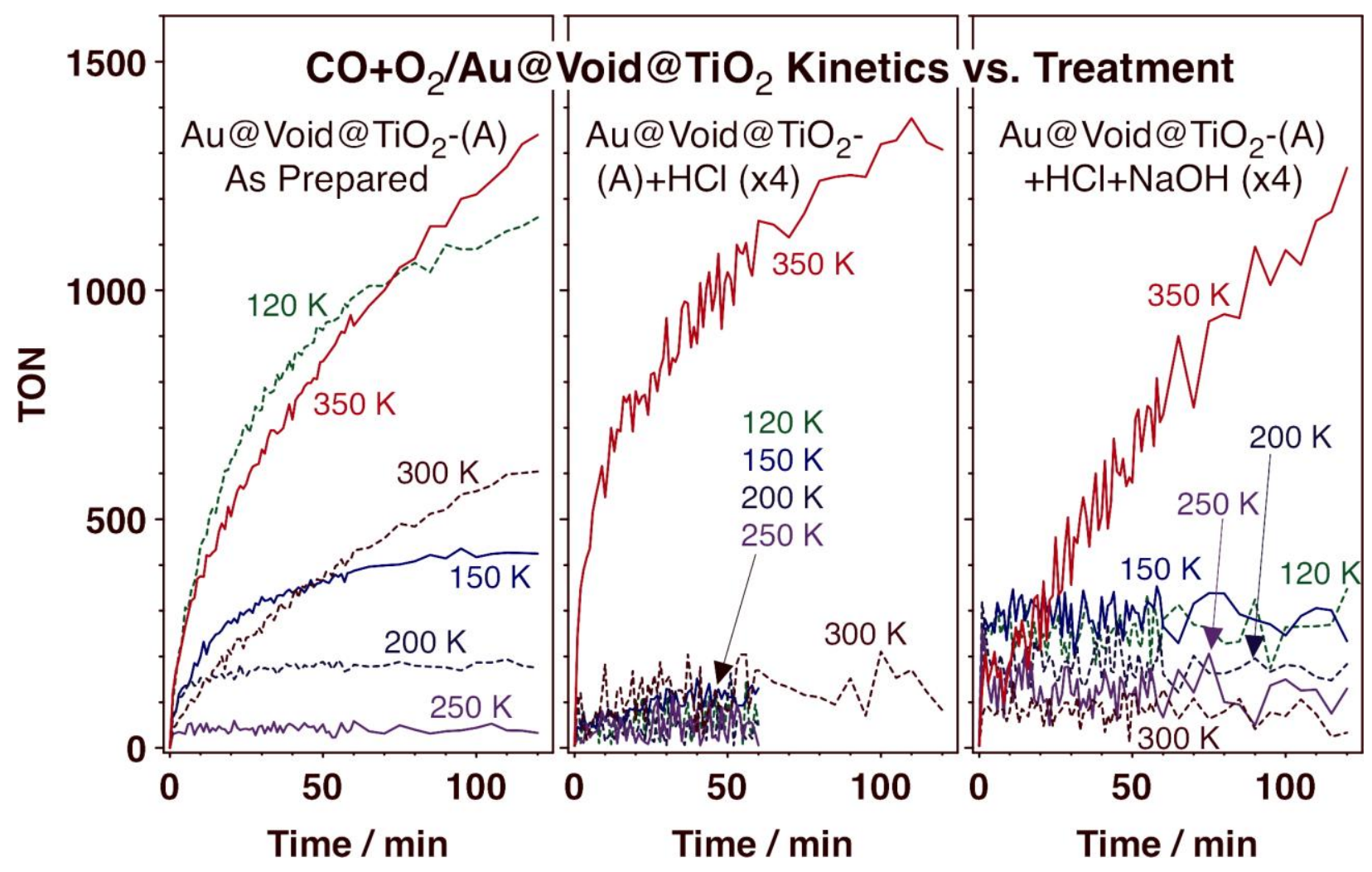

Figure 6 


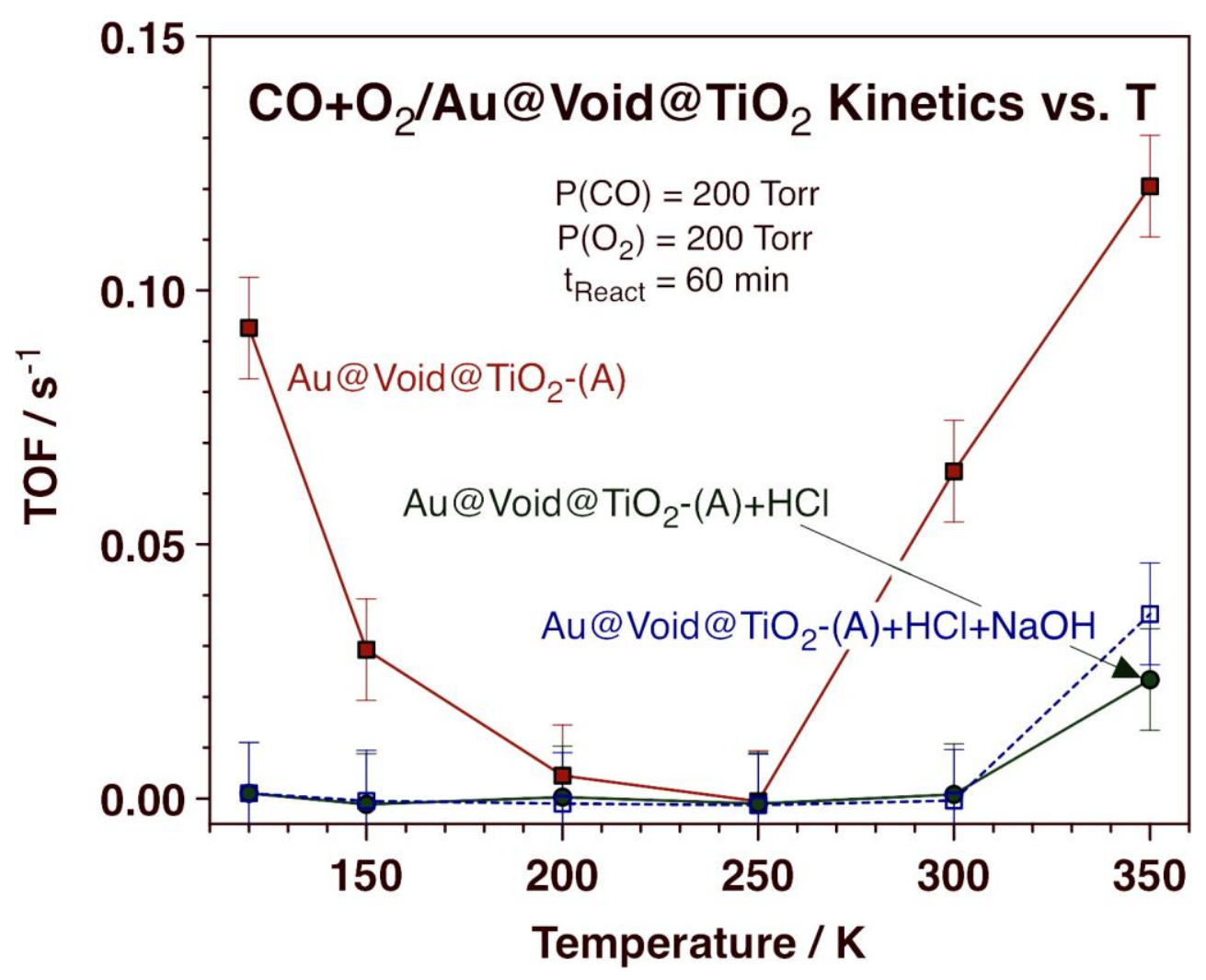

Figure 7 


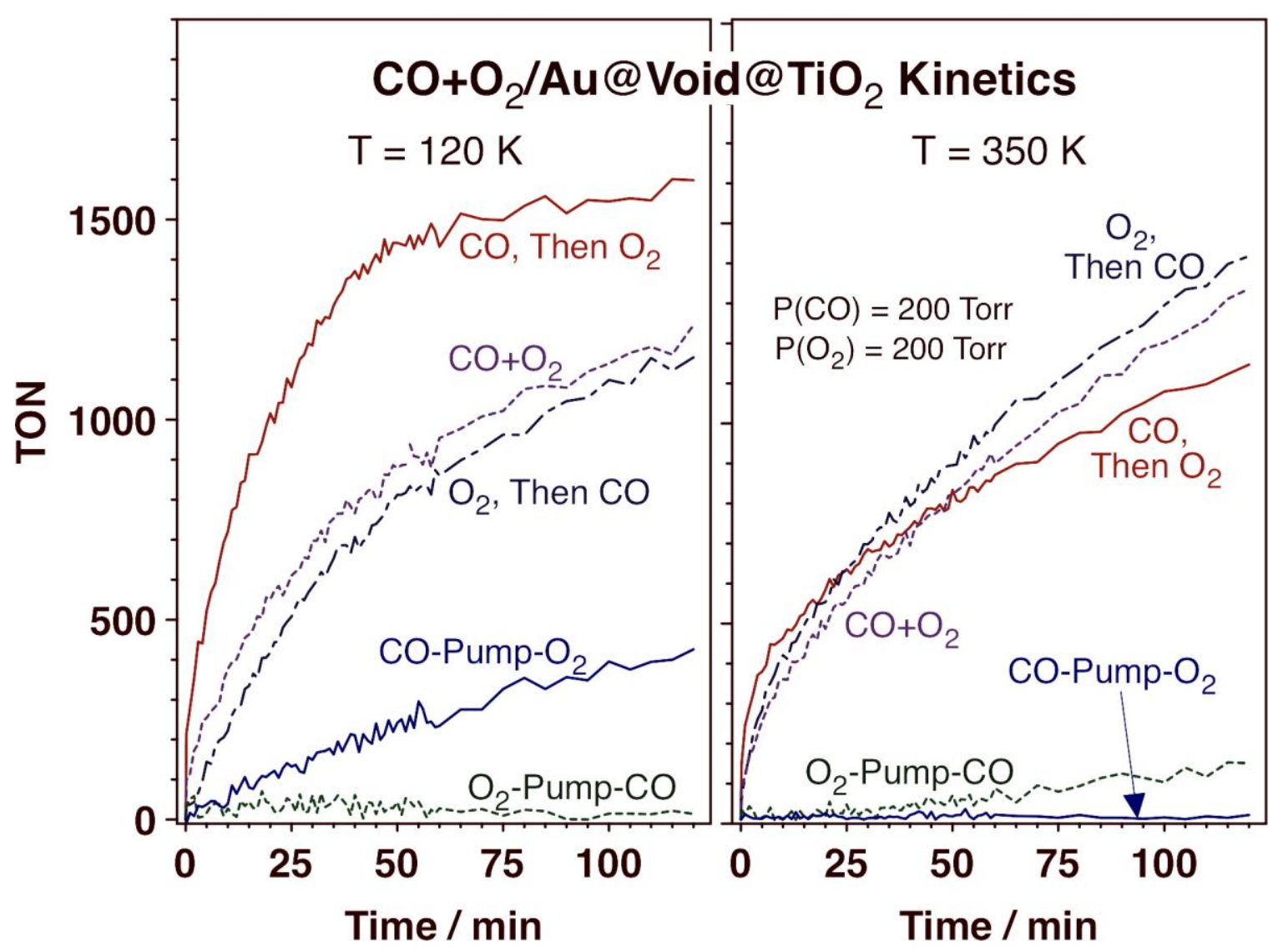

Figure 8 


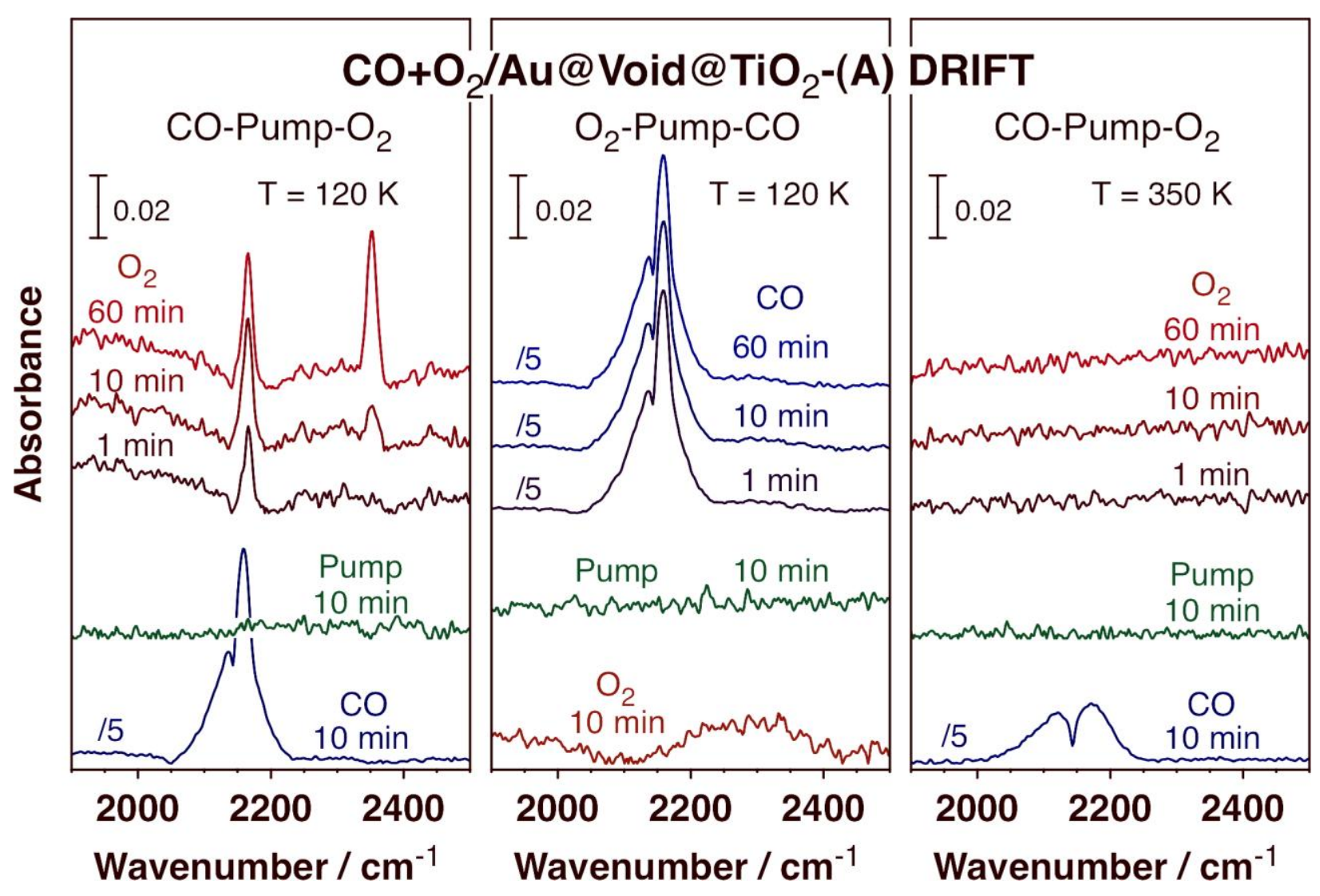

Figure 9 


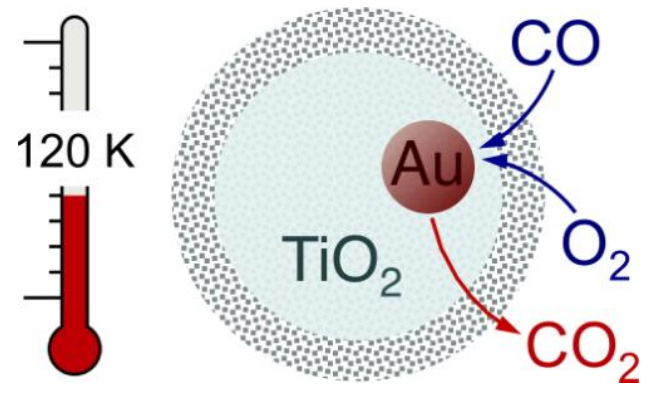

Graphical Abstract 